\title{
Notas de prosopografía novohispana (siglo XVI)
}

Juan Gil

Universidad de Sevilla

Se editan en este artículo varios documentos relativos a Catalina de Malcaida, la primera mujer de Hernán Cortés; la herencia de Hernán López de Ávila y una noticia de Diego Valadés.

Palabras Clave: Cortés, México, Nueva España, Valadés

In this article are edited some documents relating to Catalina de Malcaida, the first wife of Hernán Cortés; Hernán López de Avila and Diego Valadés.

Keywords: Cortés, México, Nueva España, Valadés.

El Archivo de Protocolos de Sevilla (APS), situado ahora en el Archivo Histórico Provincial, guarda un sinfín de escrituras relativas al Nuevo Mundo, muchas de las cuales han sido publicadas por el benemérito Instituto Hispano-Cubano de Cultura; otras las he dado a conocer por extenso en otros volúmenes de esta revista. Reúno ahora varios documentos relativos a personajes de la Nueva España que, aunque no proporcionan datos sensacionales ni cambian el rumbo de la historia (pero, ¿quién podría cambiar hoy las líneas generales de la historia salvo los políticos, que moldean el pasado a su gusto?), sí ayudan a perfilar el lado humano de los conquistadores con nuevos y curiosos detalles.

\section{Sobre Catalina Suárez de Malcaida, la primera mujer de Hernán Cortés}

Varias veces mencionó Bernal Díaz de Castillo ${ }^{1}$ a Catalina Suárez de Malcaida, la primera mujer de Cortés, aunque sin dar muchos detalles sobre su persona. Gracias al cronista sabemos, sin embargo, que Cortés se casó con ella poco antes de 1518 "por amores"; que su padre se llamaba Diego Suárez Pacheco y era oriundo de Ávila, mientras que su madre era

1 Utilizo la edición de Sáenz de Santa María, C.: Historia verdadera de la conquista de la Nueva España, CSIC, Madrid, 1982, cap. 19, pág. 37; 20, pág. 39; 136, pág. 311; 160, págs. 437, 439 y 168 , pág. 482 . 
vizcaína; que un hermano de su madre, Juan Suárez, "después que se ganó la Nueva España fue vecino y encomendado en México"; que Diego Velázquez era amigo de la familia, pues fue contrario a la boda y siempre "favoreció las partes d'ella"; que después de derrotar a Narváez Cortés escribió a su mujer a Cuba, donde vivía con su hermano, Juan Núñez; y, por fin, que la una y el otro llegaron a México con Gonzalo de Sandoval, donde a los pocos días Catalina falleció, levantando sospechas de haber sido envenenada por Cortés. En el juicio que se le puso al marqués del Valle en 1527 por asesinato se encuentran otras noticias sobre Catalina, que han sido conveniente recogidas y estudiadas por $\mathrm{H}$. Thomas. ${ }^{2}$

El documento que doy a conocer a continuación ${ }^{3}$ es el primero, a lo que sé, que habla de la desdichada Catalina, muerta con las mieles del triunfo marital en la boca (1522). Es la carta de tutela que dio el alcalde ordinario Antón Vázquez de Montalbán el 6 de octubre de 1506 en favor de la madre, María de Malcaida, vecina de Sevilla en la colación de la Magdalena, pocos días después del fallecimiento de su marido, el mercader Diego Suárez: obsérvese, dicho sea de paso, la fiabilidad de Bernal Díaz en los más pequeños detalles, como éste del nombre del padre. La escritura nos da a conocer los nombres de los hijos y su edad: Juan de Malcaida, de 19 años; Constanza Suárez, de 16; Leonor Núñez, de 13; Catalina, de 8; Diego, de 7 y Cristóbal, de 5. Indica, además, que el difunto había dejado algunos bienes muebles y raíces. Quizá por ello la viuda encontró un fiador para su oficio de tutora - para los niños menores de 18 años - y curadora — de los mayores de dicha edad - : lo fue el carpintero Pedro de Padilla, un vecino del mismo barrio y carente de educación letrada, pues era tan analfabeto como María de Malcaida. Y conviene añadir que el apellido Marcaida (o Malcaida, con el trueque fonético tan sevillano de $-r$ - por $-l-$, ayudado tal vez por una falsa etimología con $\mathrm{mal}-$ ) no es nuevo en Sevilla. En el testamento de Bartolomé dorador de 1475 aparece como su heredero un Juan de Malcaida, ${ }^{4}$ que bien podría ser el padre de María, pues sabemos que se llamaba Juan; pero me parece que más bien ha de identificarse con el Juan de Malcaida escribano que menciono en mi Prosopografía.

2 Son excelentes las páginas que le dedica en Quién es quién de los conquistadores, Barcelona, Salvat, 2001, págs. 418-22.

3 APS, III 1506 (= 1503). Lo utilicé en Los conversos y la Inquisición de Sevilla. Ensayo de Prosopografía, Fundación El Monte-Universid de Sevilla, 2001, IV, Sevilla, págs. 400-01 (y, por cierto, cometiendo el error de casar a Cortés con Constanza, y no con Catalina)

4 APS, V 1475 (= 3211), f. 2v. 
Según prueba la escritura de tutela, Catalina, la futura esposa de Cortés, tenía 8 años en 1506, el año precisamente en que Hernán Cortés, con 22, pasó al Nuevo Mundo. ${ }^{5}$ ¿Se conocieron entonces? No me parece probable. La familia de Cortés no se movió de su pueblo hasta que el triunfo de Hernán, revolucionando a todos, hizo acudir al padre rápidamente a Sevilla: en 1494 Martín Cortés era todavía un simple vecino de Medellín, pero ya hombre de autoridad, que pedía a los reyes que se apeara la heredad de Valhermoso, en término de dicha villa. ${ }^{6}$ Así, sin duda, lo era todavía en 1506. En cuanto a Hernán, debía de andar de acá para allá ocupado en otras cosas más apetecibles que en rondar a una niña que no había alcanzado la pubertad. El enamoramiento o, mejor dicho, el arrebato pasional hubo de producirse ya en Cuba, a donde pasó Catalina con sus hermanos hacia 1516 y donde la familia Suárez hubo de conocer y ganarse con sus servicios —o los coqueteos femeninos- el favor de Diego Velázquez. ${ }^{7} \mathrm{La}$ escritura en cuestión dice así:

Fecho. Tutela e cura. En la muy noble e muy leal çibdad de Sevilla, viernes, diez e seis días del mes de otubre, año del nasçimiento de Nuestro Salvador Jhesuchristo de mill e quinientos e seis años, en este día sobredicho ant'el honrado Antón García de Montalván, alcalde hordinario en esta çibdad de Sevilla por la reina nuestra $<$ señora $>, 8$ e en presençia de mí, Juan Ruiz de Porras, escrivano público de Sevilla, e de los otros escrivanos de Sevilla yusoescritos que a ello fueron presentes, paresçió y presente María de Malcaida, muger de Diego Suárez, mercader, difunto, que Dios aya, vezina d'esta çibdad de Sevilla en la collaçión de Santa María Madalena, e dixo que por quanto puede $<$ aver $* * *$ días $>^{9}$ qu'el dicho su marido avía fallesçido e fallesçió d'esta presente vida e que durante entre ellos el matrimonio ovieron e procrearon por sus fijos legítimos a Juan de Malcaida, de hedad de diez e nueve años, e a Costança Suárez, de hedad de diez e seis años, e a Leonor Núñez, de hedad de treze años, e a Catalina, de hedad de ocho

5 Así lo ha demostrado Hugh Thomas, en su espléndido libro Conquest. Montezuma, Cortés and the Fall of Old México, Simon and Schuster, Nueva York, 1994, págs. 129-30. En principio, los esponsales se podrían haber celebrado ya en 1506, porque los enlaces de entonces solían ser bastante precoces, como demuestran no ya las capitulaciones de matrimonio regias, sino también las escrituras privadas: ahí está para probarlo Antón, un niño de 12 años, desposado con María, niña de 6 años (Archivo General de Simancas, Registro general del Sello, X, n. ${ }^{\circ} 2598$, pág. 483). Pero no fue éste el caso.

6 Ibidem, XI, n. ${ }^{\circ}$ 1491, pág. 223.

7 Cf. Thomas, Hugh, Conquest, p. 134 y 785 (con referencia a AGI, Contratación, 220, parte 1 , ff. 328-342).

8 Omitido al iniciar el folio verso.

9 Espacio en blanco en el original. 
años, e a Diego, de hedad de siete años, e a Christóval, de hedad de çinco años, e que al dicho tienpo qu'el dicho su marido fallesçió el dicho su marido e ella thenían de consuno çiertos bienes muebles e raízes, e que de derecho e fuero ella es su tutora e curadora de las presonas e bienes de los dichos sus fijos, e a mayor abondamiento agora ella quería ser confirmada en el dicho cargo de ser tutora e curadora, que pedía al dicho alcalde que a su pedimiento e de su ofiçio la firme en él e le dé poder conplido, segund que de derecho en tal caso se requiere, e que jurava e jura $<a>$ Dios e a Santa María e a las palabras de los Santos Evangelios e por la señal de la Cruz, en que puso su mano derecha en manos del dicho alcalde, de usar bien e lealmente e sin arte e sin engaño alguno del dicho cargo de la dicha tutela e cura e confirmaçión; e que donde viere e ser pudiere el provecho e interese de los dichos menores sus fijos que gelo llegará, e su dapno que gelo redrará; e que los non dexará indefensos en sus pleitos e negoçios en juizio ni fuera d'él, más antes que fará e dirá e razonará todas aquellas cosas e cada una d'ellas que buenas e provechosas les sean; e quando no bastare su juizio e consejo, que lo avrá e tomará con letrados; e que todos los bienes muebles e raízes e semovientes que por ellos e en su nonbre entrare e tomare e por fuero e por derecho vençiere, que dará d'ellos e de las rentas e multiplicaçiones d'ellos buena cuenta con pago çierta, leal e verdadera a los dichos menores o a quien por ellos lo oviere de aver; e que si por su culpa o mengua o nigligençia o por su mal dezir e razonar algun<a $>$ pérdida $o$ dapno o menoscabo les viniere, que ella gelo dará e pagará todo por sí e por sus bienes muebles e raízes avidos e por aver, que para ello dixo que obligava e obligó e que renunçiava e renunçió las segundas bodas e las leyes de los enperadores Justiniano e Valiano, que son en favor e ayuda de las mugeres, que le non valiesen en la dicha razón, por quanto yo, Juan Ruiz de Porras, escrivano público de Sevilla, le aperçebí d'ellas en espeçial. E luego el dicho alcalde dixo que le dé fiança a esta dicha tutela e cura e guarda e administraçión de que quiere ser confirmada, e qu'estava e está presto de hazer justiçia. E luego la dicha María de Malcaida dixo que dava e dio por su fiador en la dicha razón a Juan de Padilla, carpintero, vezino d'esta dicha çibdad de Sevilla en la dicha collaçión de Santa María Madalena. El qual estando presente dixo que fiava e fio a la dicha María de Malcaida en el dicho cargo de la dicha tutela e cura en tal manera, qu'ella usará bien e fiel e lealmente d'ella sin arte e sin engaño alguno e dará e pagará a los dichos menores todos los mrs. e otras cosas por que fuere alcançada, e en todo fará e conplirá lo que de suso estava e se avía obligado; e si ella no toviere bienes de que lo pagar e conplir, qu'él como su fiador e con ella de mancomún e a boz de uno e cada uno ${ }^{10}$ d'ellos por el todo, renunçiando el abténtica de

10 El ms. una. 
duobus rex debendi e el beneficio de la división, lo dará e pagará a los dichos menores por sí e por sus bienes muebles e raízes avidos e por aver, que para ello dixo que obligava e obligó. E luego el dicho alcalde, visto el pidimiento a él fecho e lo que dicho es, dixo que encargava e encargó ${ }^{11}$ e confirmava e confirmó a la dicha María de Malcaida en el dicho cargo de la dicha tutela e cura de los dichos sus fijos e le dava e dio poder para que pueda tener e tenga a los dichos menores so su guarda e administraçión e para que por ellos e en su nonbre pueda demandar, dar e reçebir todos los mrs. que les sean devidos así por fin e fallesçimiento del dicho su padre como en otra qualquier manera, e reçebir en sí los mrs. e otras cosas que en su nonbre cobrare e dar cartas de pago; e asimismo para que pueda arrendar e arriende qualesquier sus bienes e posesiones a las presona o presonas e por los preçios de mrs. e otros que por ello pudiere aver e fallar, e los reçebir en sí e dar las dichas cartas de pago; e para que asimismo pueda fazer partiçión e división entre los dichos menores de los bienes del dicho su padre, segund que neçesaria sea; e sobre razón de lo susodicho obligar a los dichos menores e a sus bienes a saneamiento de todo ello e dar e fazer e otorgar en la dicha razón carta o cartas de arrendamiento o de arrendamientos e de partiçión o de partiçiones, las que neçesarias <fueren>, con las penas e firmezas que le fueren pedidas. E ella así otorgando las dichas escrituras, el dicho alcalde dixo que valan e sean firmes e valederas agora e para en todo tienpo so las penas en ellas contenidas. E otrosí dixo que le dava e dio más poder conplido generalmente contra todos los omes e mugeres que debdas deven e devieren a los dichos menores e algunas cosas les han e ovieren a dar e pagar e contra ellos han o esperan aver demanda o demandas en qualquier manera, o las tales presonas contra ellos. E sobre esta dicha razón le dio el sobredicho poder para ante la reina nuestra señora e para ante los señores del su muy alto Consejo, alcaldes e juezes de la su Casa e Corte, presidente e notarios e oidores de la su real Abdiençia e Chançillería, para ante qualquier d'ellos, e para ant'el señor arçobispo de la Santa Yglesia de Sevilla e para ante sus provisores e ofiçiales e vicarios e para ante qualquier d'ellos e para ante los otros alcaldes e juezes e fieles executores d'esta dicha çibdad de Sevilla e de toda su tierra e término e para ante qualquier d'ellos, e para ante todos los otros alcaldes e juezes e justiçias qualesquier que sean en el pleito o los pleitos <que> ovieren de aver e devieren de librar así eclesiásticos como seglares, doquier e ante quien esta carta paresçiere, para demandar e responder e menguar e conosçer e defender e pedir e requerir e querellar e afrontar e protestar testimonio o testimonios, pedir e tomar toda buena razón e exebçión e defensión, por e en nonbre de los dichos menores poner e dezir e alegar e protestar e presentar testigos e provanças e reçebir

11 Tachado a la dicha María, anticipado por equivocación. 
testigos e provanças e tachar e contradezir los que contra los dichos menores fueren dados e presentados así en dichos como en presonas e para dar e reçebir jura o juras e dar e fazer juramento o juramentos así de calupnia como deçisorio e todo otro juramento, qualquier que sea, que al pleito o a los pleitos de los dichos menores convenga de se fazer, e jurar en ánima de los dichos menores si acaesçiere por qué; e para que pueda oír sentençia o sentençias, concluir e consentir e apellar e suplicar d'ella o d'ellas e partir e tomar e seguir l'apellaçión o apellaçiones para allí e ante quien con derecho devieren ser seguidas; e para que en nonbre de los dichos menores pueda fazer e dezir e razonar así en juizio como fuera d'él todas las otras cosas e cada una d'ellas que se requieran e devan fazer e que los dichos menores farían e fazer podrían siendo de perfecta e conplida hedad; e otrosí para que en su lugar e en nonbre de los dichos menores pueda fazer e sostituir un procurador abtor o abtores, dos o más, quales e quantos quisiere e por bien toviere, así antes del pleito o de los pleitos contestado o contestados como después, e los revocar e a do quisiere tornar e tomar el poder en sí. E todo quanto la dicha María de Malcaida e los dichos sus procurador o procuradores, abtor o abtores, en el dicho nonbre fizieren e dixeren e razonaren e requirieren e querellaren e reçebieren e cobraren en todo quanto que dicho es, el dicho alcalde dizo que vala e se confirme agora e para en todo tienpo; e para que la dicha María de Malcaida <e > los dichos sus procuradores abtores puedan en nonbre de los dichos menores pedir e pidan benefiçio de restituçión in yntegrum en aquellas cosas e casos en que los dichos menores o qualquier d'ellos ayan sido lesos o engañados o dapnificados en su derecho, para que con virtud de la tal restituçión in yntegrum sean tornados e restituidos en el prístino estado en que estavan antes e al tienpo que reçebiesen la tal lesión e dapnificaçión; e si neçesaria hera relevaçión, el dicho alcalde dixo que la relevava e a los dichos sus procurador o procuradores abtores de toda carga de satisdaçión e fiadoría so aquella cláusula del derecho que es dicha en latín judiçio sisti judicium solvi con todas sus cláusulas acostunbradas. En todo lo qual que dicho es el dicho alcalde dixo que interponía e interpuso su abtoridad <e > edicto judiçial e mandava e mandó a mí, el dicho escrivano público de Sevilla, que diese esta dicha carta de tutela e cura a la dicha María de Malcaida signada con signo e firmada de su nonbre una e dos e más ${ }^{12}$ vezes, las que menester la oviese; e yo, el dicho escrivano público, de pedimiento suyo e de mandamiento del dicho alcalde, dile ${ }^{13}$ ende esta carta segund que ante mí pasó, fecha del dicho día e mes e año sobredichos, en el registro de la qual el dicho alcalde firmó de su nonbre; e los dichos María de Malcaida e Juan de Padilla no lo firmaron de sus non-

12 El ms. más e (con la e tachada).

13 Así corrijo por el enle del escribano. 
bres, porque dixeron que no sabían escrevir, e firmaron los escrivanos de Sevilla yusoescritos por ellos e por testigos. Testigos que fueron presentes a lo que dicho es Alonso de Cáçeres e Fernando de Berrío, escrivanos de Sevilla.

\section{La herencia de Hernán López de Ávila}

Los dos hijos de Ruy García de Huete, Juan de Ávila y Hernán López de Ávila, se casaron con dos sevillanas, Catalina de Vallejo y Beatriz Venegas respectivamente. Parece que Hernán participó con Cortés en la conquista de México, aunque $\mathrm{H}$. Thomas ${ }^{14}$ se inclina a suponer que llegó con Narváez. Después de la guerra López desempeñó el cargo de tenedor de los bienes de los difuntos y "fue rico a Castilla", al decir de Bernal Díaz del Castillo. ${ }^{15}$ Entre los pleitos que tuvo por su puesto (la herencia de Diego de Mendieta) se encuentra uno con el impresor Jácome Cromberger. ${ }^{16}$ Cuando le vino tempranamente la muerte, el pudiente indiano, peleado probablemente con su mujer, nombró como único heredero a su padre. Ruy García de Huete aceptó la herencia, pero falleció casi de inmediato, y la misma suerte corrió su otro hijo Juan de Avila. Toda la herencia quedaba ya para la sobrina del difunto, Juana de Avila, ${ }^{17}$ cuando Beatriz Venegas, casada ya en segundas nupcias con Rodrigo Díaz de Alfaro, ${ }^{18}$ reclamó para sí la mitad de los bienes gananciales y de las cantidades adeudadas a su primer marido. La reclamación acabó en pleito y, vista la causa en los tribunales, los jueces de la Audiencia de los Grados fallaron a favor de Beatriz. El 24 de octubre de 1534 Juana, tutelada por Catalina de Vallejo, dio poder a Beatriz para proceder al cobro de las deudas de Hernán López. Así se conserva el inventario de sus bienes y propiedades, ${ }^{19}$ que nos permiten hacernos una idea de la fortuna acumulada por los primeros conquistadores y, en nuestro caso, por un hombre de cuentas que supo volver rico.

14 Quién es quién de los conquistadores, pág. 107.

15 Verdadera historia, edición citada, cap. 204 (pág. 632); cf. cap. 174 (pág. 511).

16 Domínguez, Aurora: El libro sevillano durante la primera mitad del siglo XVI, Diputación Provincial, Sevilla, 1975, pág. 21.

17 De hecho, a ella le reclamó el mercader Alonso de Nebreda, en nombre de Sancho de Ríos y Beatriz de Villegas, una gruesa cantidad de dinero por las mercancías enviadas en 1520 por Juan de Ríos a la Nueva España (López Ocón, Leoncio-Calle, Paloma: Papeles de América en el Archivo ducal de Alba, Madrid, 1991, n. ${ }^{\circ} 118$, pág. 28).

18 Cf. sobre él mi Prosopografía, III, págs. 224-25.

19 APS, I 1534 (=47), f. $1.376 \mathrm{r}$. 
López poseía en la Nueva España gran cantidad de bienes inmuebles, esclavos y ganado: ovejas, carneros y puercos, animales que se habían aclimatado rápidamente y que en el caso de los cerdos se habían multiplicado a maravilla, tal y como había sucedido en la Española: de esta suerte, López pudo vender animales de su piara a Cortés y a Francisco de Ledesma; otro español, Pedro Fernández, le compró un caballo. La abundancia de semovientes —incluyendo en ellos a los esclavos, como se hacía a la sazón- justificó el uso de un hierro particular. Todo esto constituía ya de por sí una verdadera fortuna. Ahora bien, López, buen mercader, vendió también otras cosas a sus paisanos, sobre todo paños y sedas, que le compraban de buena gana los conquistadores enriquecidos y deseosos de hacer ostentación de lujo, desde Cortés hasta Pedro de Alvarado, Francisco de Ledesma y el factor Salazar. Sin embargo, una buena parte del dinero de Hernán López estaba colocada en otras inversiones, más arriesgadas desde luego pero mucho más lucrativas: las deudas que le debían muy diversas personas, prueba a mi juicio inequívoca de que una de las vías de enriquecimiento de López fue su condición de prestamista. Entre los deudores de Hernán López — la mayoría pertenecientes al primer grupo de expedicionarios, lo que avala la hipótesis de que también lo fuera López- se encontraba Hernán Cortés (5.200 pesos) y la flor y nata de los capitanes: Pedro de Alvarado (420 pesos), Don Pedro Puertocarrero (661 pesos), Gonzalo de Sandoval (36 pesos), Cristóbal de Olid (deuda heredada por la mujer: 130 pesos) y Diego de Ordás ( 80 pesos), hasta el propio padre Juan Díaz, el capellán de la conquista (210 pesos). Importantes cantidades le debían asimismo el factor Gonzalo de Salazar y el veedor Pedro Avilés Chirino (3.776 pesos); y es de notar que, aunque los dos se habían resistido a satisfacer la deuda, la sentencia en el juicio de mayor cuantía les fue adversa; asimismo López — un hombre de presa terco y tenaz - tuvo que pleitear para recobrar su dinero con Jorge de Alvarado y Gonzalo Domínguez. Sorprende, en cambio, que aparezcan en esta lista de morosos los nombres de Antonio de Villafañe, ahorcado por traidor en 1521, de Gonzalo Domínguez, caído en combate en marzo de 1521, y de Álvaro Maldonado, muerto antes de 1528; evidentemente, López no actualizó sus libros de cuentas, o quizá pensaba cobrar las deudas a los herederos. Para sus operaciones financieras necesitaba nuestro hombre un banquero de confianza, y éste fue Diego Martínez, uno de los más importantes cambios en Sevilla, asociado desde su instalación a su hermano García Martínez: ${ }^{20}$ de los

20 Cf. mi Prosopografía, III, pág. 428. 
oficios de la banca Martínez se sirvió todavía a finales de siglo Benito Arias Montano. Transcribo a continuación la parte más sustancial del inventario:

\section{BIENES QU’ESTÁN EN MÉXICO}

- Primeramente las casas que fueron de la morada del dicho Hernán López de Ávila, que son en la çibdad de México.

- Yten un par de casas con dos solares en la calle de Tacuba, unas casas y un solar junto cabe Sandoval en la calle enmedio.

- Yten quatroçientos esclavos herrados de hierro e señal del dicho Fernán López, los trezientos que andan cojendo oro en las minas.

- Yten un hato de ovejas e carneros en Çacatán.

- Yten otro hatillo que tiene Françisco Ramírez quatro años ha en Pánuco, que son ovejas e carneros.

- Yten çiertas yeguas e potrancas e un cavallo por padre qu'están en Çacatán.

- Yten mucha cantidad de puercos qu'están en Çacatán, que no se sabe la cantidad d'ellos.

- Yten una huerta qu'es en el camino de Chapultepeque.

- Yten un asiento para un herido de molino en Taharbayo.

- Yten tres o quatro cavallos que dexó en su casa al tienpo que d'ella se partió el dicho Hernán López de Ávila e una mula que quedó en su poder de Ruy Garçía, su hermano.

\section{DEBDAS}

- Primeramente Jorge de Alvarado le deve por sentençia seisçientos e treze pesos e seis tomines de oro.

- Yten Françisco de Lugo deve doze pesos de oro.

- Fernando de Tapia deve por una obligaçión de trezientos pesos dozientos e veinte pesos.

- Gaspar de Polanco deve por conosçimiento noventa e ocho pesos de oro.

- Santos Fernández deve catorze pesos de oro.

- Antonio de Villahañe deve por conosçimiento siete pesos de oro.

- Françisco Marruquí deve por una obligaçión que pasó ante el escrivano público de la Nueva España quinze pesos; d'éstos mandó el dicho Hernán López que se cobrasen los diez pesos, que los çinco le hizo suelta d'ellos en su testamento.

- Gonçalo Domínguez de resto de una sentençia que contra él tiene el dicho Fernán López deve veinte e ocho pesos de oro. 
- Juan Vélez el Moço deve por conosçimiento quatro pesos.

- Diego de Ordás deve de resto de ochenta pesos de oro treze pesos, porque los demás le pagó Françisco de Orduña por él, como lo confiesa por el dicho su testamento.

- Alonso de Ávila, vezino de México e señor de Boytecán, deve de resto de trezientos e quarenta e dos pesos de oro çiento e veinte pesos por una carta mesiva qu'está en poder del governador.

- El padre Juan Díaz deve por conosçimiento de resto de dozientos e sesenta e un pesos doziento $<$ s $>$ e diez pesos.

- Niculás de Gibraltar deve de resto de una obligaçión de mayor contía treinta e quatro pesos.

- Diego de Valdenegro deve çinquenta pesos de oro; e todo lo demás que paresçiere qu'éste le deve al dicho Fernán López, se lo suelta por el dicho testamento.

- Diego Martín, banquero del dicho Fernán López de Ávila, le deve quinze pesos de oro, los quales son por conçierto que hizo a Alonso de Ávila, vezino de la Nueva España.

- Christóval Flores deve ochenta pesos de oro, de los quales el dicho Fernán López mandó en su testamento que se descontase el mahíz que le dio segund él lo dixere e declarare.

- La muger de Christóval de Olí deve çiento e çinquenta e dos pesos.

- Gonçalo de Sandoval deve por una carta mesiva treinta e seis pesos de oro.

- Alonso Gallego el de la guardia le deve diez e nueve pesos de oro que le prestó.

- Miguel Estevan le deve quatroçientos e çinquenta pesos de oro.

- Françisco de Haça deve treinta pesos, los quales son qu'el dicho Fernán López de Ávila pagó por él a Miguel de Morales.

- Álvaro Maldonado le deve por un conoçimiento dozientos e dos pesos de oro e seis tomines.

- Gonçalo del Canpo le deve dozientos pesos de oro de minas.

- El señor governador Hernando Cortés deve tres mill e seisçientos pesos de oro, que se los prestó el dicho Fernán López; e d'esto se a de descontar todo lo que paresçiere qu'él resçibió, qu'está asentado en el libro del dicho governador.

- Pedro Rodríguez de Carmona le deve quarenta pesos de minas que le prestó.

- Pedro Fernández, vezino de Çacatula, le deve çinquenta pesos de minas de un cavallo que le vendió.

- El fator Gonçalo de Salazar deve por sentençia seis mill e seisçientos e sesenta e seis pesos de oro. 
- Asimismo deve el fator Gonçalo de Salazar otros çiento e çinquenta e ocho pesos e quatro tomines.

- Yten asimismo deve el dicho fator por otra sentençia de çiertas sedas nueveçientos pesos de oro.

- Yten el veedor Pedro Avilés Cherino de resto de una sentençia de mayor contía deve tres mill e seteçientos e setenta e seis pesos de oro.

- Yten Françisco de Ledesma, vezino de la Nueva España, deve çiento e sesenta pesos de oro, los ochenta de unos puercos que le vendió el dicho Fernán López e lo demás de çiertas ropas de paño e seda que le vendió.

- Yten deve el señor governador mill e seisçientos pesos de oro, los quales son qu'el dicho Fernán López se los dio en cosas de ropa e paño e seda e puercos e en dozientos pesos de oro que le dio a dar por Luis de Fustamente, segund paresçerá por el libro de Santa Cruz que hizo.

- Yten deve el liçençiado Marcos de Aguilar ocho platos de platas del tamaño de los qu'el dicho Fernand López dexó en Nueva España e un jarro de plata grande.

- Yten deve Pedro de Alvarado qu'está en la Nueva España quatroçientos e veinte pesos de oro de cosas de ropa e otras cosas de refresco que le dio, segund paresçerá por las memorias que le dexó allá.

- Yten deve Don Pedro Puertocarrero qu'está en la dicha Nueva España por una obligaçión seisçientos e sesenta e un pesos de oro.

- Yten deve Françisco Núñez qu'está en la Nueva España dozientos e diez pesos de oro por una obligaçión.

- Yten deve Françisco Núñez otros quarenta pesos de oro que pagó por él a Juan de Cáçeres a quien devía çien pesos.

\section{Noticia de Diego Valadés}

Parece probable que Diego Valadés, uno de los soldados que participaron en la conquista de México, sea el padre de fray Diego de Valadés, el famoso autor de la Rhetorica christiana, a pesar de las razonadas dudas que ha arrojado sobre su origen en un estudio modélico el padre Isaac Vázquez. ${ }^{21}$ Los textos latinos autobiográficos de Valadés aducidos por Palomera y que discute Vázquez son ambiguos y pueden interpretarse tanto a favor como en contra de la tesis tradicional. Tiene razón I. Vázquez al tachar de incorrecta la traducción que hace Palomera de la frase en que Valadés se llama a sí mismo eius terrae fere alumnus ("por haber sido yo

21 "Fray Diego Valadés. Nueva aproximación a su biografía” en Actas del II Congreso Internacional sobre los franciscanos en el Nuevo Mundo, Madrid, Deimos,1988, pág. 843 y sigs. 
criado desde mi niñez en esa tierra"); pero podría interpretarse "por ser casi hijo de esa tierra", esto es, mitad español y mitad indio, y no de la manera - también posible- que propone Vázquez, "por haber yo casi nacido y crecido en esa tierra". Otro argumento que esgrime Vázquez es que Valadés cifra en 30 años su período de estancia en la Nueva España, cuando tendría que haber dicho 38 ó 39, de modo que esos años que faltan serían los que habría pasado fuera de las Indias; sin embargo, los cómputos cronológicos de los autores, que gustan de hablar con números redondos, inducen a veces a error si se les da excesivo crédito: ¿se podría reconstruir la biografía de Colón de atender a las fechas a veces inconexas que da en sus escritos? En cambio, creo que acertó Palomera cuando entendió que el postquam Europaeorum uidi caerimonias de otro pasaje indica que Valadés nunca estuvo en Europa (España incluida) antes de dejar México; es la interpretación más sencilla que cabe hacer a la afirmación de Valadés: "ninguna de las catedrales de España iguala aquella magnificencia de las iglesias [de México], como afirman muchos varones dignos de crédito que estuvieron en uno y otro país y como yo puedo atestiguar, una vez que he visto las ceremonias de los europeos". Por último, el que Waddingo lo llamara Hispanus en vez de Mexicanus es un argumento reversible, pues podría muy bien explicarse como una cortesía del gran cronista hacia el mestizo, al resaltar su sangre española y olvidar misericordiosamente la indígena.

Sea como fuere, creo de interés dar a conocer unos poderes que ilustran el origen de Valadés: el primero, un poder general de Diego a varios familiares dado en la "grand çibdad de Tenuxtitán México" el 28 de mayo de 1530, y el segundo una carta de pago de su tío Juan Lucas al mercader Diego Fernández del 17 de enero de $1533 .{ }^{22}$ Gracias a estas dos escrituras queda ahora esclarecido que Diego Valadés era natural de Villanueva de Barcarrota - lugar de donde partieron muchas personas a buscar fortuna en el Nuevo Mundo en el siglo XVI y donde se ha rescatado hace unos años la famosa biblioteca emparedada entre paja - y que sus padres fueron Alonso Sebastián Valadés, muerto ya en 1530, y Catalina Martín. Precisamente a su madre envió Valadés 106 pesos por medio del mercader Diego Fernández Caso, con la mala fortuna de que el dinero llegó a su destinataria cuando ésta había fallecido ya. El tío, Juan Lucas, se hizo cargo en nombre de Valadés del envío monetario, que se vendió en Sevilla a 390

22 APS, I 1533, $1(=43)$. 
mrs. el peso. Tiene su importancia para la cultura de los conquistadores que tanto Diego Valadés como su tío Juan Lucas supieran escribir. Este superior nivel cultural hace más comprensible la futura dedicación a las letras de fray Diego.

Sepan quantos esta carta vieren cómo yo, Diego Valadés, natural que soy de la villa de Villanueva de Valcarroto, qu'es en el maestradgo de Alcántara de los reinos de Castilla, vezino que soy d'esta grand çibdad de Tenuxtitán México d'esta Nueva España del Mar Oçéano, otorgo e conozco que do e otorgo todo mi poder conplido, libre e llenero bastante segund que lo yo he e tengo e de derecho más puede e deve valer a Catalina Martín, mi madre, muger que fue de Alonso Sebastián Baladés, difunto, que Dios aya, e a Juan Lucas, mi tío, e a Pedro Maçías, mi primo, todos vezinos de la dicha villa de Valcarrota, a todos tres juntamente e a cada uno d'ellos por sí in solidum, generalmente para todos mis pleitos e cabsas e negoçios así movidos como por mover que yo he e tengo e espero aver e tener contra todas e qualesquier persona o personas que sean.... En firmeza de lo qual otorgué esta carta de poder ant'el escrivano e notario público e testigos de yuso escritos, que fue fecha e otorgada en la dicha çibdad de Tenuxtitán México, estando en ella la corte e chançellería de Su Magestad, a veinte e ocho días del mes de mayo, año del nasçimiento de Nuestro Salvador Jhesuchristo de mill e quinientos e treinta años. E el dicho Diego Baladés lo firmó de su nonbre en el registro d'esta carta. Testigos que fueron presentes a lo que dicho es Fernán Medel e Gaspar de la Plata, escrivanos de Su Magestad, e Diego Calero, vezinos d'esta dicha çibdad, e yo, Juan Fernández del Castillo, escrivano de Su Magestad e su escrivano e notario público en la su corte e en todos los sus reinos e señoríos. Presente fui a lo susodicho en uno con los dichos testigos e lo fiz escrevir e fiz aquí mi signo atal en testimonio de verdad Juan Fernández del Castillo, escrivano e notario público.

Sepan quantos esta carta vieren cómo yo, Juan Lucas, vezino que so de Villanueva de Barcarrota, que es en el maestradgo de Alcántara, en nonbre e en boz de Diego Valadés e por virtud del poder que d'él tengo, su thenor del qual es éste que se sigue... otorgo e conozco en el dicho nonbre que he resçebido de vos, Diego Fernández Caso, mercader, vezino que sois d'esta çibdad de Sevilla en la collaçión de Sant Niculás, qu'estades presente, çiento e seis pesos de oro de minas de diez e nueve quilates cada peso, los quales son qu'el dicho Diego Valadés dio a vos, el dicho Diego Fernández, en la çibdad de México qu'es en la Nueva España, para los dar a Catalina Martín, madre del dicho Diego Valadés, la qual es fallesçida d'esta presente vida. Los quales dichos çiento e seis pesos de oro se vendieron en esta dicha çibdad de 
Sevilla a presçio cada peso de trezientos e noventa maravedíes, los quales vos me distes e pagastes por virtud del dicho poder de suso encorporado e los yo resçibí e son en mi poder, de que so e me otorgo de vos por bien contento e pagado.... Es fecha la carta en el ofiçio de Alonso de la Barrera, escrivano público de Sevilla, viernes, diez e siete días del mes de enero, año del nasçimiento de Nuestro Salvador Jhesuchristo de mill e quinientos e treinta e tres años. Testigos que fueron presentes Fernand Garçía de Baeça e Pedro de Toledo, escrivanos de Sevilla. E el dicho Juan Lucas firmó su nonbre en el registro. 